\title{
Hardware base and experimental potential of a smart building prototype
}

\author{
Arina Mokhireva ${ }^{1 *}$, Polina Loginova ${ }^{1}$, Ekaterina Glebova ${ }^{1}$, and Vladimir Bespalov ${ }^{1}$ \\ ${ }^{1}$ Peter the Great St. Petersburg Polytechnic University, St. Petersburg, Russian Federation
}

\begin{abstract}
The concept of a model of a building for laboratory interdisciplinary experimental research to systems of a smart house is offered. At the first stage, the principal provisions of the future experiment are determined, the core of the system is constructed and its functional capabilities are determined. As a result, the Arduino-based processor was adopted as the core of the system, a circuit was built that reads data from two sensors and outputs control signals. The principle of assembly of a layout is developed, allowing to expand a control kernel and to connect any number of modules a lot at home. The main modules of the smart house have been determined, which will be experimentally investigated first. These are energy management modules from solar and wind power plants and control of the entire power system of the house, a coordination module with the BIM model, a structural monitoring module, ventilation, air conditioning and water supply modules, a dynamic layout module, and an Internet module for things and object tracking.
\end{abstract}

\section{Introduction}

By now, there is widespread automation of buildings and their functionality. Since the 1990s, such concepts as "smart buildings" and "smart cities" have appeared. At the same time, the construction industry has not yet fully integrated these technologies [1]. Automation and intelligent control systems the buildings functional designs projects separately from architectural and constructive solutions and is installed in already constructed buildings. This greatly limits the capabilities of such systems, and some of them cannot be realized at all. In this regard, it is necessary to conduct complex automation systems with architectural and planning solutions and building designs. This combination offers many opportunities for expanding the functional and leads to a rethinking of the very concepts of residential and public buildings. To explore such opportunities, it is necessary to conduct a large amount of experiments with smart buildings. In conditions of real heights associated with the determination of the high cost of structures, equipment and labour required work. Such studies are advisable to carry out when adaptation of the developed tools to the behaviour of people is required, in conditions of actual operation [2-10]. At the same time, such studies can be carried out on reduced scale models of buildings with full preservation of the functionality of all devices. At the same time, one of the most important requirements for such models is the maximum approximation to the real parameters of buildings in materials,

*Corresponding author: mohirevaarina@mail.ru 
structures and schemes of engineering networks. Small dimensions of the layout are important to ensure the variability of experimental conditions and the ability to quickly change the assembly under study.

In addition to the development of new functional systems, the layout may allow the development of existing studies. For example, the technology of photogrammetry and laser scanning [11-13] can be combined with a smart house system to track the position of objects and people. This will improve the Internet technology of things [14-16] and in itself will be one of the important functions of a smart home. Intelligent house technology allows you to take a new level of monitoring of structures and building surveys. The existing methods of monitoring are rather laborious and do not always allow an unambiguous conclusion about the state of the structures $[17,18]$. Within the framework of the model, it is possible to study methods for monitoring structures using a network of autonomous sensors located inside the bearing and enclosing structures and on the exterior surfaces of the building [19]

Systems for monitoring and tracing items and structures have great potential within the framework of the BIM concept for the design and operation of buildings [20-23]. The tracking system allows to optimize the processes of erection of buildings, including the economic component. In addition, since the entire history of the movement of people, machines and equipment on the site becomes known, the consequences of potential production errors are minimized, which reduces the risks of the project [24, 25]. And the monitoring system enables real-time monitoring of the state of the facility and in the future to automate the forecasting of the development of any defects and the designation of repair measures. Within the framework of the layout, it is possible to effectively develop and explore a bunch of such systems with the BIM model of the layout.

Connecting to the smart house systems of solar and wind energy systems and watersaving supply systems is a full-fledged development of the principles of green building [2631]. For these systems, it is advisable to develop a common electric power management system, including communication with external networks, lighting control and electric heating [32-39].

Existing studies [39-45] of smart home systems are carried out either in existing buildings or on conditional mock-ups that play only a decorative role, which narrows the possibilities of such studies. In this regard, the authors proposed to conduct a series of experimental studies of various modules of a smart house on a mock-up of a low-rise building that is as close as possible to real analogues. The purpose of this article is to define the concept of the experiment, the possibilities for research, the main directions of research and the necessary hardware basis

\section{Methods}

The experimental model is created for the purpose of carrying out a series of interdisciplinary studies. For the supporting structures of the model, ceramic bricks of 1:20 scale, cement mortar and 1:20 scale rolled steel on bolted connections will be used. The estimated dimensions of the layout will be up to $1200 \times 1200 \times 1200 \mathrm{~mm}$, to ensure compactness and transportability. Finishing materials, enclosing structures, partitions and thermal insulation will be assigned based on the tasks of specific ongoing studies of these or other modules. The design of the layout is supposed to be made partially modular for the possibility of dismantling individual elements, changing the configuration of the layout and installing additional equipment and sensors.

A mock-up is a prototype of a low-rise building, which can be either a private residential building, or a multi-apartment or public building. Thus, the scope of using the results of the experiments will cover most of the civil engineering. 
Within the first stage of the experiment, the Arduino board was chosen as the hardware basis of the system (Pic. 1, a), which is the most convenient and affordable platform for developing electronic devices. Sensor systems, motors, displays and remote-control devices can be connected to it, which will be programmed to communicate and interact with each other.

a)

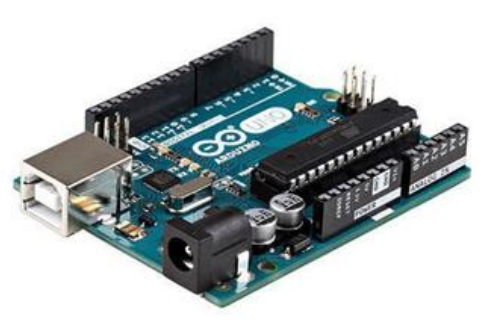

c)

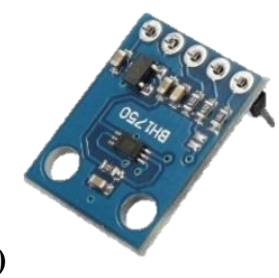

b)
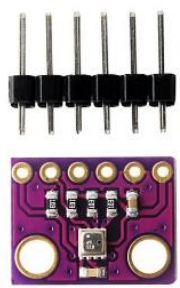

d)

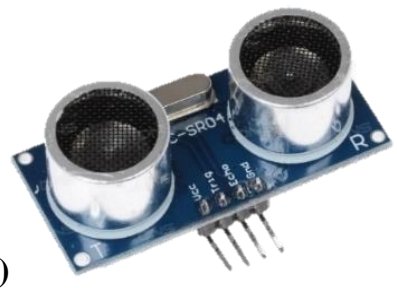

Fig. 1. Devices used in the first stage of assembly and testing of the layout. a - Arduino Uno board; b - atmospheric pressure and temperature sensor BMP280; $\mathrm{c}$ - light intensity sensor GY302; $\mathrm{d}$ - ultrasonic range finder HC-SR04

The microcontroller on the board is programmed using the Arduino language (based on the Wiring language) and the Arduino development environment (based on the Processing environment). Projects of devices based on Arduino can work independently or interact with the software on the computer.

To assess the performance of the board, a part of the sensors of the ventilation and airconditioning control system (Pic. 1, b) and lighting were also taken (Pic. 1, c, d).

For the initial study, 2 systems were chosen: a lighting control system, a heat regulation system. For his research at the initial stage was built a simplified frame model of the room. Metal plates of large cross-section to create floors overlap, metal plates of small cross-section to create a frame base of the walls, corner plates to strengthen the joints of the faces of the walls of the room were chosen as the elements of the connection metal hex nuts. Built frame model of the room has the following dimensions: the overlap $-15 \times 15 \mathrm{~cm}$, height of walls $15 \mathrm{~cm}$ For the convenience of the study as a form of layout of the room was chosen square. For each system under study, a similar design was created.

As the first experiment, the study of the lighting system of the room was chosen. The choice of this sensor is due to the efficiency of integration with a full-fledged "Smart home" system that provides comfortable accommodation and increases the energy efficiency of the building. In the previously created metal frame of the room model, a light intensity sensor GY-302 was introduced, the work of which is based on the illumination of the room from the amount of external light penetrating into the room. The components of the light intensity sensor are described by schemes that allow to determine the level of illumination and on the basis of the data provided, to adjust the illumination of the rooms of the house. Decisive 
parameters are the ambient light level and the light level of areas inside the building. The scheme of this installation was developed earlier in the program Grasshopher, Rino and is shown in figure 2.

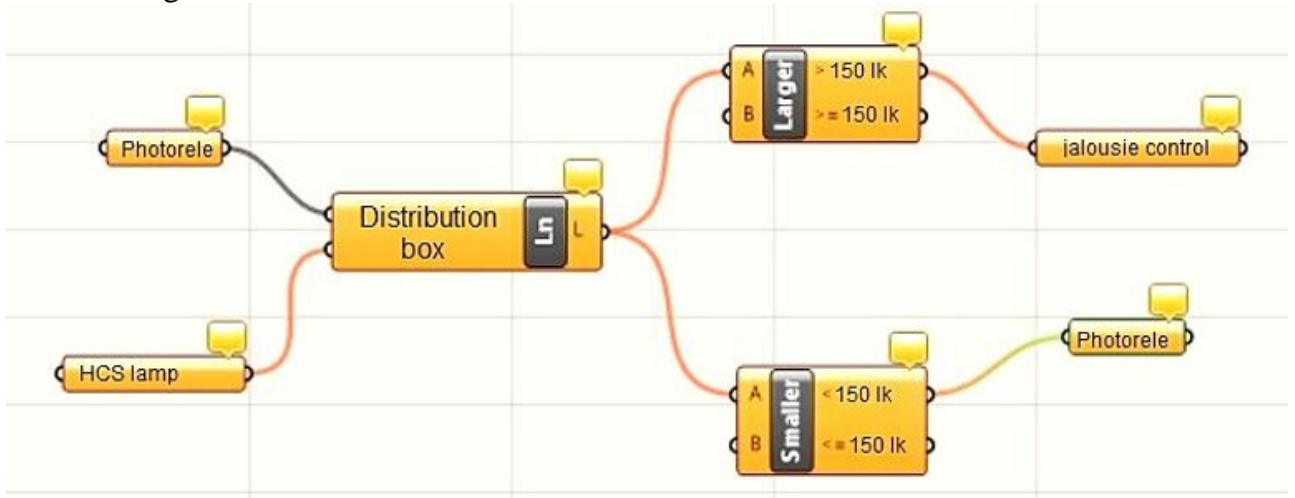

Fig. 2. Scheme of the block «Lighting Control»

Thanks to the light intensity sensor will be external and internal regulation of light by changing the position of the shutters of the light from the outside, and the regulation of internal lighting of the house lamps. External light sources in the daytime are the sun, at night - artificial street lighting. The sensor must be connected to the household electrical network. The sensor is suitable for the phase and neutral conductors. There is also a third pin connecting the signal to the lighting line. In this case, this pin will connect the shutter control system. The resistance of the sensing element changes depending on the illumination. The less light, the greater the resistance. When the set voltage is reached, the sensor sends a signal to the amplifier, which drives the relay. Taking into account the necessary conditions for the placement of the sensor, namely:

- The height of the installation should not be too high, as the sensor will have to be periodically serviced: clean from dust and dirt, wipe.

- The installation location must prevent the vehicle headlights from entering the sensor.

- $\quad$ Lighting fixtures should be removed as far as possible.

- It is necessary to ensure unhindered sunlight on the sensor for its correct operation [46].

The following layout of the sensors was developed as shown in figure 3.

Light sensors located outside the window, inside the window and in the corner of the room to control the degree of illumination. This arrangement allows you to effectively analyze the level of light in the room. To automatically turn on the light when a person is in the room as a built-in motion sensor (ultrasonic rangefinder HC-SR04). In addition, there will be installed a system of manual control on/off light and brightness control for maximum personalization of the smart home.

During the experimental testing of these sensors, their installation was carried out according to the scheme in figure 3. The sensor was connected to the Arduino. A conditional object was entered and submitted to the layout. When making an ultrasonic rangefinder triggered on the movement of the object and the light was turned on. In parallel to the control platform, a light intensity sensor and a turning element were connected. The sensor was exposed to the required level of illumination of the room. When simulating a bright light source from the outside of the layout, the corresponding light sensor set in motion the rotating shutters of the relay to control the light level. As a result, the main drawback of this system was revealed - the need for accurate calculation of the angle rotation with excessive external 
lighting level. Integrating the internal light sensor into this system revealed the same problem. The most optimal solution is to write code that takes into account the degree of change in external sources.

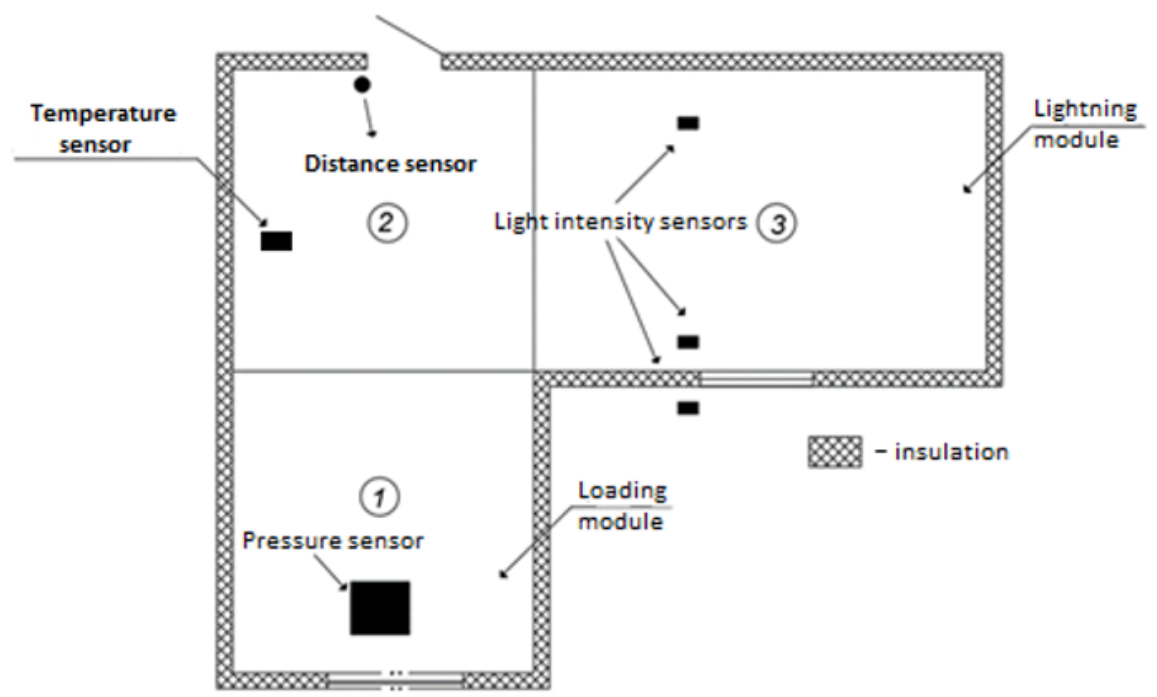

Fig. 3. The layout of the sensors.

To study the temperature control system, a simplified model of the room was created on the basis of a steel frame, mineral wool, cardboard, a heating element, a temperature sensor BMP280, a USB cable, a carefree breadboard (PRT-12002), wire jumpers with plugs at both ends, wire jumpers with a plug at 1 end and a socket at the other.

To connect the sensor to the Arduino, power is supplied to the power output, the signal output is connected to the analog output Jack of the platform. The temperature sensor produces a voltage that has a linear dependence on the temperature rise. The left pin is connected to the positive power $+5 \mathrm{~V}$, the right pin to the negative (ground). The diagram of the received connection is shown in the figure. At a temperature of 25 degrees Celsius on the signal output voltage of $0.750 \mathrm{~V}$.

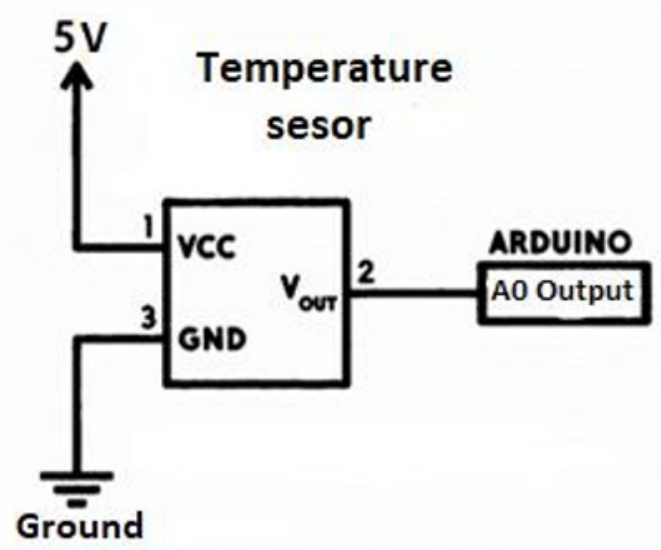

Fig. 4. The sensor in thermoregulation

To control the heating element when the temperature changes, it will be connected directly to the Arduino platform. If the set temperature is exceeded, the heating element will 
be switched off. If the temperature is lower than the set temperature, the heating element will be switched on.

To create a program code for controlling the temperature control system, the Arduino IDE version 1.6.5 was used. It was used for several functions, in particular the conversion of the output voltage of the sensor at any temperature in the temperature reading in degrees Celsius, a function of turning on/off the heating element when changing the specified temperature range.

As a result, the efficiency of this method of monitoring the temperature of the room was revealed. Studies on the simplified layout and their analogy BIM model in Grasshopper show that most research with practical results is possible to do using the building information model.

\section{Results and Discussion}

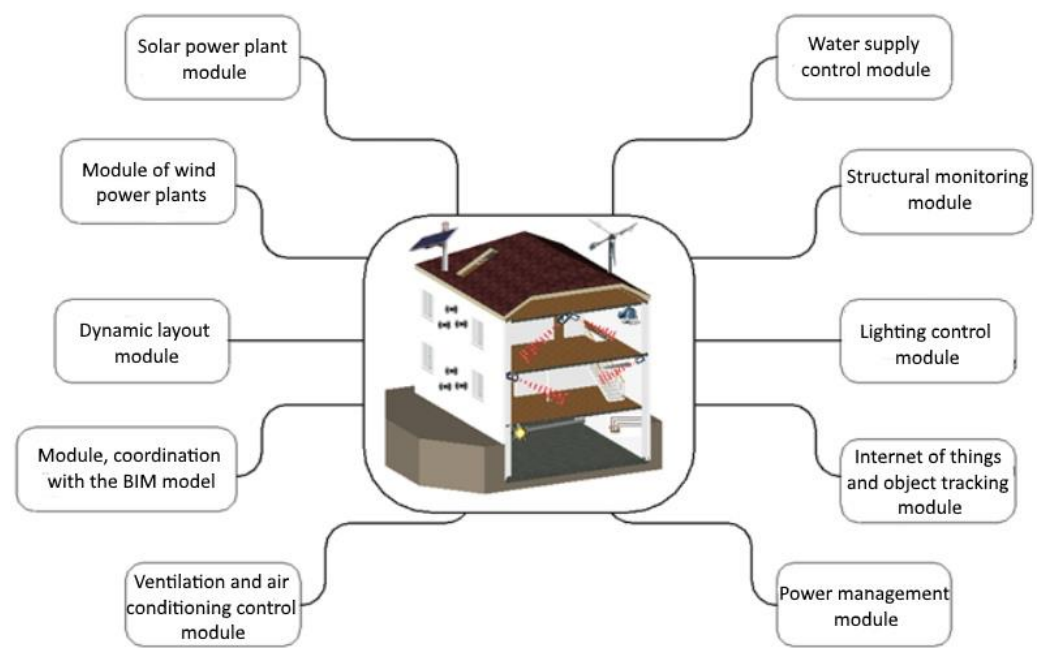

Fig. 5. The main experimental modules of the designed prototype

The presented model makes it possible to implement experimental studies in parallel in several directions (Fig.5).

The first studies will include energy management modules from solar and wind power plants. They can be done before the completion of the layout. The research will be aimed at the development of such an energy management system that would allow optimizing the use and accumulation of solar and wind energy while minimizing energy consumption from external networks, as well as conducting input monitoring of external networks through sensors that record deviations and transmit information to the central cloud for warning faults and emergency situations. With this system, a lighting control system and external lighting control must also be connected.

Before the construction of the layout, its BIM-model will be developed, in conjunction with which it is expected to investigate most of the systems. The model will be expanded and supplemented with the construction of the layout and the connection to it of certain modules, and also in the future, when developing new modules.

During the construction of the layout in the load-bearing structures it is supposed to lay pressure and humidity sensors to investigate the module of monitoring the smart house and its subsequent connection with the BIM-model. The sensors for monitoring indoor parameters and tracking the position of objects are mounted at the final stage of the layout assembly. To provide power to all sensors and sensors, there are two alternatives. At the 
initial stage - from batteries, then from a wireless power source with the development of an appropriate method of placing energy sources and transmitting resonators.

Modules of ventilation and water supply control are envisaged, which are supposed to be investigated in conditions of changing environmental parameters in the layout rooms and various situations that go beyond the usual operational impacts, such as fire, pipelines leakage, extremely low ambient temperatures, etc.

A separate module will be a dynamic planning system, within which the possibilities of moving non-structural elements of structures, including in automated mode by means of remote control, will be explored.

To ensure the operation of these systems, it is necessary to select a control card that will connect the sensors and sensors of the control environment to the existing equipment and contain a programmable control module, on which you can write the program code from an external computer. In the first stage, the Aruino UNO board was selected and a circuit (Figure 3) was selected, containing three sensors that would be used in the layout.

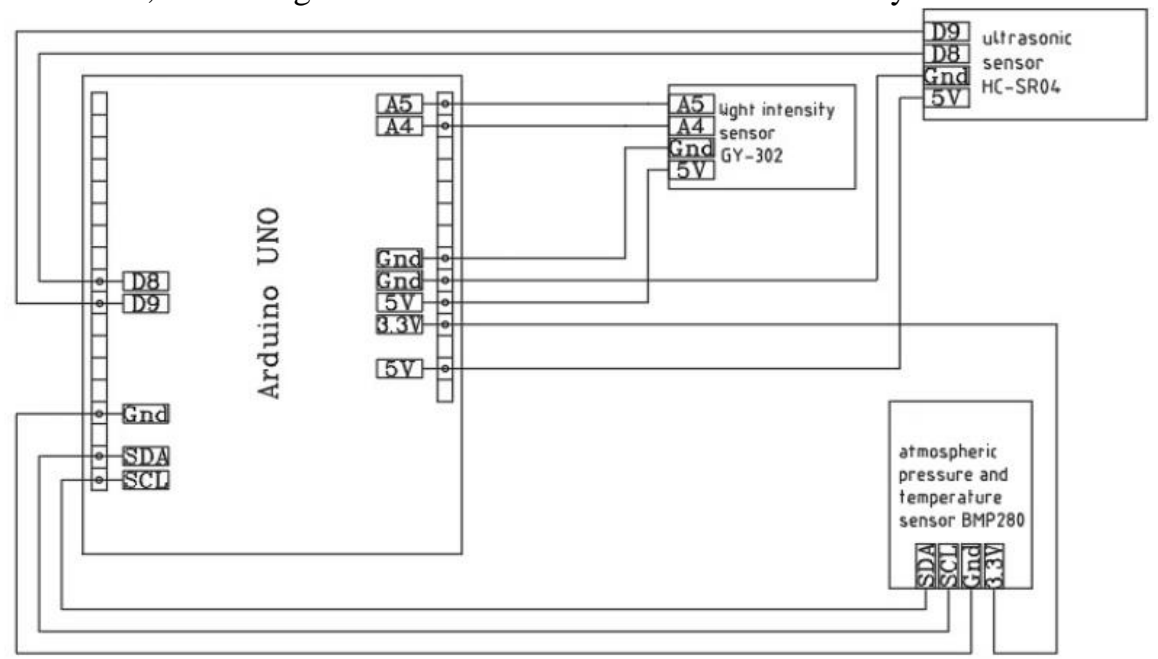

Fig. 6. A scheme of connecting sensors to the control board

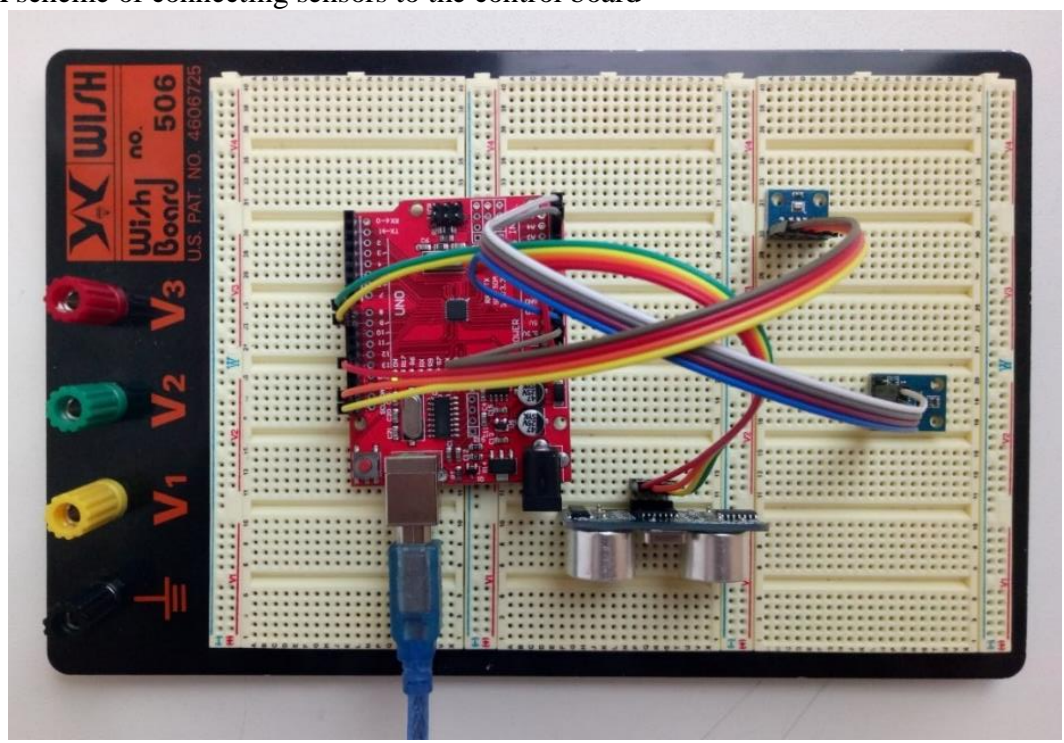

Fig. 7. The assembled circuit connected to the PC for data output 
The ultrasonic rangefinder (distance sensor) HC-SR04 generates sound pulses at a frequency of $40 \mathrm{kHz}$, and by the reflected signal determines the distance to the object. Programmatically comparing the readings of the sensor, we can determine the fact of moving the object and the direction of its movement. The light intensity sensor GY-302 is a highprecision digital sensor based on the BH1750 chip. It is widely distributed in photo and video cameras, smart home systems, mobile devices due to high accuracy (distinguishes more than 60 thousand gradations of light), and almost complete absence of reaction to radiation outside the visible spectrum of light (for example, infrared radiation), which means, that the sensor "sees" the same light as the human eye. Based on the data coming from the ultrasonic sensor in the doorway, the system will determine whether the user entered or went out, and the street light intensity sensor will determine the degree of illumination, and accordingly the need to turn on the light in the room.

The atmospheric pressure and temperature sensor BMP280 will be connected to the air conditioner as a control element, and, according to the sensor, it will adjust the intensity of its operation.

For the circuit assembled from these elements, a code is written that uses all the sensors to collect information and process it, the end result is not transferred to the existing equipment within the first stage but is output to a text file on an external computer connected to the Arduino board. Further, lighting and air conditioning systems can be included in this scheme, where commands will be sent.

In the course of the study, the conditioning and lighting functions were tested on the assembled circuit (Fig. 7) with the output of conditional control commands to a text file on a PC. It has been determined that it is not always appropriate to use this method of switching on the light, because the user does not always need to turn off the light after leaving the room and vice versa, turn on after entering. Also, a hindrance to using this method can be the use of it in small rooms, such as storerooms and bathrooms, where errors in reading the movement of the user can occur. Solve these problems in several ways, such as programmatically delayed switching off lights in certain rooms (different for rooms of different profiles) or establishing a connection between the sensors in different rooms in order to most accurately determine the user's movements and the need to turn off the light. Unequivocally it is necessary to install an additional system of manual lighting control, so that in a particular situation the user himself could decide whether to leave the light on. These problems need to be investigated in the future on the completed layout of the building.

The Arduino UNO card used in the first stage has the ability to connect 12 different elements, such as sensors or working equipment. Also, as one of the elements, another Arduino board can be connected, which significantly expands the possibilities of connecting new modules. In addition, the board has built-in open source software that is convenient for solving various problems of programming smart home systems. In connection with this, such boards will be adopted as a hardware basis for the experimental layout. However, there are other management cards that can be used. They can also be considered in further comparative studies as an alternative to Arduino.

Such studies of smart home systems will be conducted with all its components. BIM models in Grasshopper and Autodesk Revit programs will be designed to predict the results. The advantage of these hardware systems is the ability to parameterize the components of the system and setting their brands and labels, which will calculate the cost of the structures used.

Comparing the study with the study [24], it is possible to identify additional areas of project development associated with the introduction of BIM technologies and their application for commercial purposes, such as a full assessment of the proposed solutions in the technical equipment of the house. The study [15], which presents a specially created mobile application for Android. It used a built-in ambient light sensor to trigger a new closed- 
loop feedback algorithm to implement daylight acquisition. Cost analysis shows that the entire system setup is a bit cheaper than traditional commercial products. Because of the possibilities of daylight accumulation, it has the potential to save money in the long run, ahead of current commercial products. This confirms the expediency of the created model. In particular, each study is reduced to the monetary component of all works.

\section{Conclusions}

The main modules of the smart house have been determined, which will be experimentally investigated first. These are energy management modules from solar and wind power plants and control of the entire power system of the house, a coordination module with the BIM model, a structural monitoring module, ventilation, air conditioning and water supply modules, a dynamic layout module, and an Internet module for things and object tracking.

The hardware and software basis is offered on the basis of the Arduino card, which allows to manage all the proposed systems, and, if necessary, to extend the experiment, to connect additional boards. This approach allows virtually unlimited expansion of the functional of the system.

Research will need to be conducted at the junction of construction, information and computer sciences, instrumentation technology and modern electric power industry. However, despite the complexity of these experimental studies, their results can significantly affect the design and construction of residential and public buildings and increase the functionality of buildings.

\section{References}

1. A.O Mohireva., P.V. Loginova, E.M. Melehin, V.I Kostarev, Alfabuild, 2 (4), 7-20 (2018).

2. L. Barkhuus, A. Vallgårda, Adjunct Proceedings of UbiComp, 165-166 (2014).

3. D.J. Cook, A.S. Crandall, B.L. Thomas, N.C. Krishnan, Computer, 46 (7), 62-69, (2013)

4. S.F. Chien, H.J. Wang, Frontiers of Architectural Research, 3, 376-385, (2014)

5. P. Foroudi, S. Gupta, U. Sivarajah, A. Broderick, Computers in Human Behavior, 80, 271-282, (2018)

6. H. Yao, X. Wang, L. Wu, D. Jiang, D. Liang, Procedia Engineering. 211, 1111-1114, (2018)

7. K.A. Nguyen, R.A. Stewart, H. Zhang, C. Jones, Applied Soft Computing. 31. 118-131. (2015)

8. M.S. Ahmed, A. Mohamed, T. Khatib, H. Shareef, R.Z. Homod, J. Abd Ali, Energy and Buildings. 138, 215-227, (2017)

9. E. Papadopoulou, S. Gallacher, N.K. Taylor, M.H. Williams, Pervasive and Mobile Computing. 8. 485-499. (2012)

10. D.D. Zaborova, K.I. Strelets, Bruges J. Bonivento, M.I. Asylgaraeva, M. de Andrade Romero, C. Steffan, Magazine of Civil Engineering. 4(80). 104-118. (2018)

11. V.V. Korenev, N.S. Orlova, A.V. Ulybin, S.D. Fedotov, Construction of Unique Buildings and Structures. 2(65). 40-58. (2018) (rus)

12. D.V. Nemova, Magazine of Civil Engineering 37, (2013), doi:10.5862/MCE.37.4F. Poux, P. Hallot, R. Neuville, R. Billen, 11th 3D Geoinfo Conference. Athens. 4-2. 119127. (2016)

13. W.G. Drossel, F. Meinel, A. Bucht, H. Kunze, Procedia Manufacturing. 21. 197-204. (2018) 
14. S. Brad, M. Murar, Construction of Unique Buildings and Structures. 5 (20). 15-27. (2014)

15. M. Rathore, A. Paul, W. Hong, H. Cheol Seo, I. Awan, S. Saeed, Sustainable Cities and Society. 40. 600-610. (2018)

16. O.Yu. Sudar, A.V. Ulybin, G.A. Kukushkina, Construction of Unique Buildings and Structures. 5 (44). 58-71. (2016) (rus)

17. S.V. Korniyenko, N.I. Vatin, A.S. Gorshkov, Construction of Unique Buildings and Structures. 6 (45), 34-54. (2016) (rus)

18. M. Iommi, Energy and Buildings. 158. 1450-1460. (2018)

19. A.N. Astafieva, J.A. Kibireva, I.L. Vasileva, Construction of Unique Buildings and Structures. 2017. 8(59). 41-62. (rus)

20. N. Vatin, A. Gorshkov, P. Rymkevich, D. Nemova, D. Tarasova, Applied Mechanics and Materials 670-671, 365-369 (2014), doi:10.4028/www.scientific.net/AMM.670671.365 .

21. M. Heidari, E. Allameh, B. de Vries, H. Timmermans, J. Jessurun, F. Mozaffar, Automation in Construction. 39. 134-144. (2014)

22. N.V. Braila, K.L. Khazieva, A.A. Staritcyna, Magazine of Civil Engineering. 6. 70-77. (2017)

23. M. Petrichenko, N. Vatin, D. Nemova, N. Kharkov, A. Korsun, Applied Mechanics and Materials 672-674, 1903-1908 (2014)

24. T.V. Bobrova, P.M. Panchenko, Magazine of Civil Engineering. 8. 84-97. (2017)

25. S.V. Kornienko, E.D. Popova, Construction of Unique Buildings and Structures. 4(55). 67-93. (2017) (rus)

26. N. Vatin, D. Nemova, L. Khazieva, D. Chernik, Applied Mechanics and Materials 635637, 2057-2062 (2014), doi:10.4028/www.scientific.net/AMM.635-637.2057

27. E. Aronova, N. Vatin, V. Murgul, Procedia Engineering. 117. 766-774. (2015)

28. L. Romanach, Z. Leviston, T. Jeanneret, J. Gardner, Energy Procedia. 121. 238-245. (2017)

29. M. Shakeri, M. Shayestegan, S.M. Salim Reza, I. Yahya, B. Bais, M. Akhtaruzzaman, K. Sopian, N. Amin, Renewable Energy. 125. 108-120. (2018)

30. E.A. Loktionova, D.R. Miftakhova, Magazine of Civil Engineering, 8, 214-224 (2017)

31. V.A. Kostenko, N.M. Gafiyatullina, G.S. Zulkarneev, V.N. Starkov, Construction of Unique Buildings and Structures, 6(57), 47-55 (2017)

32. J. Reynolds, Y. Rezgui, J.-L. Hippolyte, Sustainable Cities and Society, 35, 816-829 (2017)

33. Z. Hadas, L. Janak, J. Smilek, Mechanical Systems and Signal Processing, 110, 152-164 (2018)

34. A. Bariri, L. Roseiro, J.A. Millryn-Garcia, I. Grimez-Arriaran, M. Odriozola-Maritorena, Energy and Buildings, 149, 321-328 (2017)

35. K. Gkoumas, F. Petrini, F. Procedia Engineering, 199, 3444-3449 (2017)

36. W.F. Chien, H.J. Wang, Frontiers of Architectural Research, 3, 376-385 (2014)

37. H. Fathabadi, Energy Conversion and Management, 80, 543-549 (2014)

38. D.U. Bulanchik, A.P. Kiryushina, Construction of Unique Buildings and Structures, 11(62), 15-24 (2017) (rus)

39. Y.-X. Lai, C.-F. Lai, Y.-M. Huang, H.-C. Chao, Information Sciences, 230, 39-55 (2013)

40. G.P.R. Filho, L. A. Villas, H. Freitas, A. Valejo, D. L. Guidoni, J. Ueyama, Computer Networks, 135, 54-69 (2018)

41. S. Muller, J. Krebber, P. Smeele, Speech Communication, 48, 1-27 (2006)

42. G. Başol, R. Güntürkün, E. Başol, World Wide Journal of Multidisciplinary Research and Development, 3 (6), 53-58 (2017) 
43. S. Tang, V. Kalavally, K. Yew Ng, J. Parkkinen, Energy and Buildings, 138, 368-376 (2017)

44. A. Piccolo, F. Simone, Energy Procedia, 78, 110-115 (2015)

45. A. Mohireva, P. Loginova, E. Melehin, V. Kostarev, AlfaBuild, 2(4), 34-42 (2018)

$[1-3]$

1. N. Vatin, A. Gorshkov, P. Rymkevich, D. Nemova, D. Tarasova, Applied Mechanics and Materials 670-671, 365-369 (2014), doi:10.4028/www.scientific.net/AMM.670-671.365.

2. M. Petrichenko, N. Vatin, D. Nemova, N. Kharkov, A. Korsun, Applied Mechanics and Materials 672-674, 1903-1908 (2014), doi:10.4028/www.scientific.net/AMM.672-674.1903.

3. N. Vatin, D. Nemova, L. Khazieva, D. Chernik, Applied Mechanics and Materials 635-637, 2057-2062 (2014), doi:10.4028/www.scientific.net/AMM.635-637.2057. 